
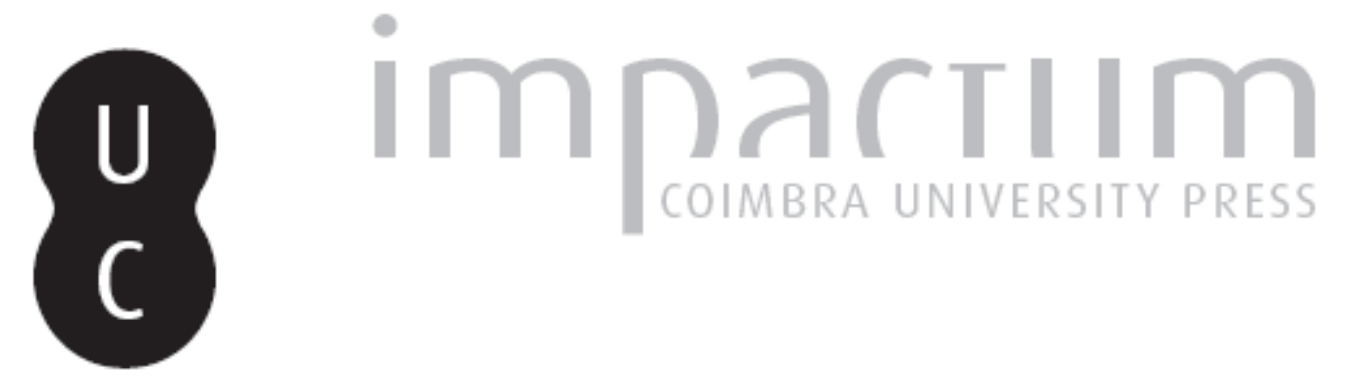

\title{
llustrados e Inquisición ante la iglesia constitucional francesa
}

Autor(es): $\quad$ Parra López, Emilio la

Publicado por: Imprensa da Universidade de Coimbra

URL persistente:

URl:http://hdl.handle.net/10316.2/43780

DOI:

DOI:https://doi.org/10.14195/2183-8925_10_21

Accessed : $\quad$ 26-Apr-2023 06:46:12

A navegação consulta e descarregamento dos títulos inseridos nas Bibliotecas Digitais UC Digitalis, UC Pombalina e UC Impactum, pressupõem a aceitação plena e sem reservas dos Termos e Condições de Uso destas Bibliotecas Digitais, disponíveis em https://digitalis.uc.pt/pt-pt/termos.

Conforme exposto nos referidos Termos e Condições de Uso, o descarregamento de títulos de acesso restrito requer uma licença válida de autorização devendo o utilizador aceder ao(s) documento(s) a partir de um endereço de IP da instituição detentora da supramencionada licença.

Ao utilizador é apenas permitido o descarregamento para uso pessoal, pelo que o emprego do(s) título(s) descarregado(s) para outro fim, designadamente comercial, carece de autorização do respetivo autor ou editor da obra.

Na medida em que todas as obras da UC Digitalis se encontram protegidas pelo Código do Direito de Autor e Direitos Conexos e demais legislação aplicável, toda a cópia, parcial ou total, deste documento, nos casos em que é legalmente admitida, deverá conter ou fazer-se acompanhar por este aviso.

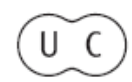


REVISTA DE HISTORIA DAS IDEIAS IO
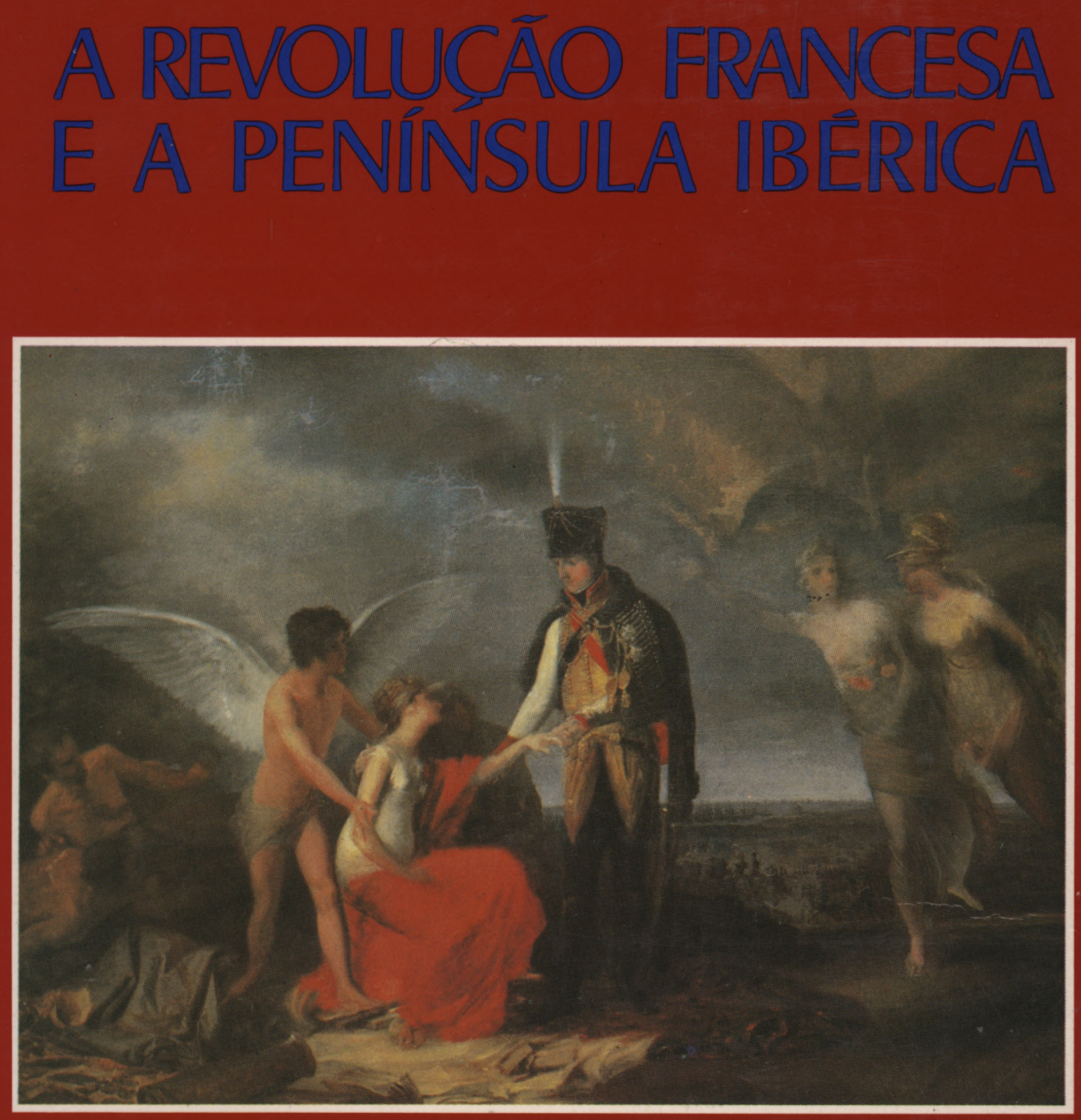

INSTITUTO DE HISTÖRIA E TEORIA DAS IDEIAS FACULDADE DE LETRAS 
EMILIO LA PARRA LOPEZ *

\section{ILUSTRADOS E INQUISICIÓN ANTE LA IGLESIA CONSTITUCIONAL FRANCESA}

\section{Información bibliográfica sobre los acontecimientos franceses}

El 10 de octubre de 1792 Saubaigne, ciudadano de Bayona, envía varias cajas de libros a Estanislao de Lugo, residente en Madrid. Este cargamento es examinado minuciosamente el mes siguiente por los funcionarios reales y de la Inquisición en la aduana de Agreda (Soria) quienes relacionan 254 obras; algunas de ellas se hace constar llegan por duplicado y triplicado. Todas están escritas en lengua francesa, incluso las que se deben a autores ingleses (Locke, Hume, Paine...) e italianos (Filangieri); en la lista no se consigna ninguna obra de autor español. Además de los escritos más notorios de los filósofos (Voltaire, Rousseau, Condorcet, D'Holbach, Helvetius, Mably, Volney...) y de varias publicaciones sobre el sistema político de Estados Unidos de América, sobresalen en el envío los títulos alusivos a los sucesos de 1789 y a la iglesia constitucional. Estamos, por consiguiente, ante una biblioteca completa sobre la Revolución Francesa ( $\left.{ }^{(}\right)$.

Acerca de los acontecimientos revolucionarios, aparte de varios relatos detallados y extensos $\left({ }^{2}\right)$, los fondos examinados

\footnotetext{
* Universidad de Alicante.

(1) Archivo Historico Nacional, Madrid (A.H.N.), Estado. leg. 3143.

(2) Entre los libros sobre este tema están. por duplicado, la Colection complète des travaux de Mirabeau l'aîné à l'Assemblée Nationale (Paris. 1791, 5 tomos), ed. por E. Mesan, De l'Insurection Parisienne et de la prise de la Vastille 「sicl. de Dusaulx (Paris, 1790) v el famoso folleto sobre el Tercer Estado de Sièves. Resaltemos. asimismo, una extensa Histoire de la révo'utionn de 1789 et de l'établissement d'une Constitution en France (Paris, 1790, 7 tomos), de autor no consig-
} 
abundan en obras relativas a la nueva constitución política francesa. El texto constitucional de 1791 aparece en una edición sin fecha, realizada en Paris, que incluye «la Gran Carta de Inglaterra»; en otro volumen, recibido por duplicado, sin año ni lugar de edición, y en otro más, también duplicado, en el que está el texto en francés, inglés e italiano $\left(^{3}\right)$. Sobre los derechos del hombre, junto a la clásica obra de Mably, Des droits et devoirs du citoyen, en la edición de Kell, 1789, se envían a Lugo un Cathécisme des droits de l'homme (Paris, 1791) y las obras de Thomas Paine Théorie et pratique des droits de l'homme (Paris, 1792) y Droits de l'homme et réponse a l'attaque de $M r$. Burke (Paris, 1791-92, 2 tomos).

Basten estas anotaciones para percatarnos del carácter de la información bibliográfica destinada a Estanislao de Lugo. En esta ocasión nos importa detenermos sólo en un tipo de cbras: las relativas a la iglesia constitucional francesa. Sobre este asunto la información es abundante y minuciosa, y si bien no es necesario reseñar los 37 títulos directamente relacionados con el tema, sí conviene mencionar algunos. En primer término, las cartas pastorales de obispos juramentados. En la lista constan ocho pastorales, escritas por los prelados de La Sarthe, La Meurthe, Paris, Seine et Oise, Seine et Marne, Seine-Inferieure, Loire et Cher y L'Ardeche. Se trata de varios de los obispos constitucionales más distinguidos en la defensa de la Constitución Civil del Clero, que fueron, además, caracterizados polemistas con los clérigos refractarios. En algunos casos. además de la pastoral se reciben otras obras. Así, de Grégoire consta también, por duplicado, su escrito sobre la Legitimité $d u$ serment civiaue exigé des fonctionnaires ecclésiastiques. Del obispo Luc François Lalande, de la Meurthe, llega una Défense et justification de la lettre pastorale.... (Nancy, 1791), escrita como respuesta a las acusaciones vertidas contra su pastoral por los obispos no juramentados de la Lorena. Del prelado de Seine-Inferieure, Jean Baptiste Gratien, hay asimismo otra obra, ésta por duplicado, Contraste de la réformation anglicane par Henri VIII et la réformation gallicane par L'Assemblée Constituante, escrita siendo vicario de la catedral de Chartres.

nado en esta relación, y Précis historique de la Révolution française, de J.P. Bravant (Paris, 1790), entre otros varios volúmenes sobre el mismo tema.

(3) La lista incluye también un folleto de $21 \mathrm{pp}$. titulado Proyet de Constitution, Preliminaire de la Constitution del abate Sièyes (s/f) y Analyse, dictionnaire et texte de la Constitution française (Paris, 1791). También consta por duplicado una colección completa de las disposiciones de la Asamblea Constituyente, en dos tomos. 
Y del metropolitano de París, Gobel, junto a la pastoral mencionada consta un Mandement, editado en 1791, y una Lettre en réponse à celle de $M$. Charrier de la Roche.

Las obras que acabamos de consignar de Grégoire, Lalande y Gratien contienen las ideas fundamentales de la Iglesia constitucional francesa. No obstante, la información destinada a Lugo no paraba ahí: se completa con otros libros publicados igualmente para justificar la obra eclesiástica de la Asamblea Constituyente. Hemos mencionado los cinco volúmenes de los discursos de Mirabeau en la Asamblea, entre los que cabe suponer se incluían los relativos a las disposiciones eclesiásticas y su defensa de la Constitución Civil del Clero. En esa publicación debió figurar también el «adresse aux français» de Mirabeau a propósito de la Constitución Civil del Clero, llamamiento redactado por Adrien Lamourette, elegido metropolitano constitucional de Lyon en marzo de 1791. En la lista de Lugo figura, asimismo, una obra de Lamourette, Prônes civiques ou le Pasteur patriote, en cinco volúmenes (Paris, 1791), que se recibe por duplicado.

En este mismo envío aparecen otros libros que, junto con los mencionados, constituyen el catálogo de las mejores publicaciones francesas aparecidas en 1791-92 en defensa de la iglesia constitucional. Consta por triplicado la principal obra colectiva escrita por los obispos juramentados en favor de la Constitución Civil del Clero: Accords des vrais principes de l'église, de la morale et de la raison sur la Constitution Civile du Clergé, Paris, 1792. Se trata, probablemente, de una segunda edición del escrito aparecido por primera vez en 1791, firmado por 18 obispos diputados en la Asamblea, que contiene, además, una Lettre des évêques constitutionnels au pape. Esta obra fue la respuesta de los constitucionales al manifiesto de los prelados, también diputados, contrarios a la Constitución Civil del Clero, publicada con el titulo de Exposition des principes sur la constitution civile du clergé, aparecido el 30 de octubre de $1790\left(^{4}\right)$. La afición de Lugo a los escritos de los obispos constitucionales queda corroborada por otra obra, recibida por duplicado: Supplément à l'ouvrage des évêques constitutionnels, redactada, según el título, por un oratoriano (Paris, l'an I).

Aparte de otros escritos con títulos tan significativos como La Théologie reconciliée avec le patriotisme.... (Paris, 1791, 2 tomos, duplicado) o Défense de Richer.... (Paris, 1790) cabe destacar dos libros debidos a sendos laicos. El uno es obra del

(4) Dictionnaire de Théologie Catholique, Paris, 1908, voz: "Constitution Civile du Clergé» (vol. III, p. 1558). 


\section{Revista de História das Ideias}

magistrado Durand de Maillane, caracterizado jansenista y miembro del Comité Eclesiástico de la Constituyente: Histoire apologétique du Comité Ecclésiastique de l'Assemblée Nationale (Paris, 1791) recibido por duplicado. De otro laico, también integrado en el jansenismo francés, el abogado Noël Larriére, llegan tres ejemplares del Préservatif contre le schisme, ou questions relatives au Décret de 27-XI-1790 (Paris, 1792).

La información sobre la iglesia constitucional y acerca de los sucesos revolucionarios en general es completa, pero unilateral. Están ausentes de esta lista los autores contrarrevolucionarios $\mathrm{y}$, en cuanto a los asuntos religiosos, ningún escrito ataca, al parecer, la política seguida por la Asamblea Constituyente. No hay obras de Maury, del conde de Antrigues, de Sénac de Meilhan... y, lo más sorprendente, no están en esta lista la famosa Histoire du clergé pendant la Révolution française de Barruel ni las publicaciones del controvertido Jabineau, el antiguo jansenista distinguido por sus polémicas con Gratien y por su ataque a la Constitución Civil del Clero. Resulta clara, por consiguiente, la orientación ideológica de Lugo, lo cual parece lógico a juzgar por la trayectoria del personaje.

\section{Estanislao de Lugo, un personaje clave}

A finales de 1792 , cuando se produce el envío de libros a que nos venimos refiriendo, el caballero Estanislao de Lugo es una persona influyente. Está bien relacionada con la Corte, donde actúa como preceptor del hijo mayor del infante D. Luis, ocupa un cargo burocrático en la Secretaría de Gracia y Justicia y es íntimo amigo de la condesa de Montijo, una dama que reune en su casa a un importante grupo de ilustrados, clérigos y laicos, quienes, a su vez, desempeñan distintos cargos de influencia $\left({ }^{5}\right)$.

Lugo pertenece al sector de ilustrados españoles calificado como «jansenista». En él se incluyen casi todos aquellos que deseaban cambiar la iglesia española. La característica común fue la convicción episcopalista y regalista y la oposición a los jesuitas, motivo determinante este último para otorgarles el calificativo de jansenistas. Muy influidos por los escritores fran-

(5) Vid. G. Demerson, «Un canarien 'éclaire': D. Estanislao de Lugo (1753-1833n), Mélanges à la mémoire de Jean Sarrailh, Paris, 1966, pD. 311-329; y P. De Demerson, María Francisca de Sales Portocarrero (Condesa del Montiio). Una figura de la Ilustración, Madrid, Editora Nacional, 1975, pp. 94-95. 
ceses, estos ilustrados coinciden en lo esencial con los planteamientos galicanos y antirromanistas de buena parte de los reformistas europeos. Al finalizar la centuria el núcleo del grupo radica en Madrid. El lugar clave allí es la casa de la condesa de Montijo, donde confluyen casi todos: ahí van los canónigos de San Isidro, foco jansenista por excelencia, entre quienes se cuentan Antonio Oliveros y Antonio Posada; los discípulos directos o indirectos de Gregorio Mayans, como J. L. Villanueva; Jovellanos, Meléndez Valdés y otros laicos empleados en diversos oficios reales, y cuantos clérigos que, bien por relaciones personales con los nombrados, bien por convicciones propias, desean la reforma eclesiástica en la línea conocida como «jansenista».

Los estudios de Mestre, Saugnieux, Appolis, P. de Demerson, etc. nos eximen ahora de especificar más en torno a estas personas. No obstante, apuntemos algunos aspectos al caso. Con Carlos III algunos de estos personajes habían trabajado en la reforma de los Colegios Mayores y de los planes de estudio de las universidades. En los años noventa parecía llegado el momento de afrontar otros asuntos, hasta el punto de considerarse posible la mutación de muchos puntos de la «disciplina externa» de la Iglesia. La Asamblea Constituyente francesa demostró cómo podía efectuarse la reforma eclesiástica desde el poder temporal, sin el permiso previo del Papa, inconveniente retardatario en todo momento para este tipo de empresa. Las reformas francesas, por otra parte, cuadraban en gran medida con los proyectos forjados por los ilustrados españoles, consistentes en la creación de una iglesia nacional estructurada en torno a los obispos y a los párrocos, en una reordenación de los bienes del clero, la reorganización territorial de diócesis y parroquias... y en la reforma de las órdenes religiosas. Franceses y españoles, además, coincidían en la admiración hacia el Sínodo de Pistoia, fuente doctrinal de ambos en lo relativo a cuestiones litúrgicas y en lo concerniente a las prácticas de piedad y otros asuntos de importancia.

La coincidencia de propósitos no era nueva. Precísamente Estanislao de Lugo personifica con notable claridad el contacto y la forja de planes comunes con los franceses antes de la Revolución. Desde 1787 mantiene correspondencia con el abate Clément. La defensa de las reformas de Pistoia y la lucha contra los jesuitas, considerados estos últimos los auténticos obstáculos para conseguir cambios en la iglesia española, ocupa la atención primordial de esta correspondencia $\left({ }^{6}\right)$. Las alteraciones

( ${ }^{\theta}$ E. Appolis, Les Jansénistes espagnols, Bordeaux, Sobodi, 1966, pp. 107-108. 
introducidas por la Constitución Civil del Clero y la doctrina manifestada por los primeros escritos de los constitucionalistas franceses tenían, necesariamente, que entusiasmar a Lugo. En consecuencia la orientación de las obras enviadas desde Bayona no es en absoluto sorprendente.

Hemos visto cuando reseñábamos esas obras que varias de ellas llegaban por duplicado y triplicado. Precísamente se da tal circunstancia en los libros menos dudosos doctrinalmente, es decir, aquellos que constituyen una defensa directísima de la iglesia constitucional. No sería aventurado suponer que Lugo, como hombre clave en el grupo de ilustrados españoles y persona de la máxima confianza de la condesa de Montijo, con la que contrajo matrimonio poco después (en 1795), estuviera encargado de distribuir la bibliografía entre sus amigos.

Ahora bien, illegaron estos libros examinados en la aduana de Agreda a manos de su destinatario? No he hallado en el Archivo Histórico Nacional de Madrid sobre este caso concreto más documentación que la ya citada y en ella, aparte de la lista detallada de libros, sólo consta que se examinaron, sin más anotación. Con todo existen fundados motivos para suponer que parte de los libros enviados en 1792 llegaron a manos de Lugo, pues en 1817 poseía varios de ellos. En septiembre de ese año la Inquisición hace un registro en casa de Lugo y halla, además de obras de Rousseau, Volney, Locke, etc., todos contenidos en la lista de 1792, "varias historias de la revolución francesa" (así lo anota el inquisidor, Fr. Ildefonso Bueno), colecciones de «epístolas y evangelios» en francés, la Constitución de la República francesa, una pastoral del arzobispo de París, etc. $\left({ }^{7}\right)$.

En los años noventa fue notable la confusión en las aduanas en punto a la revisión de libros. Tras las medidas drásticas de Floridablanca se pretendió regular este asunto mediante una Real Orden fechada en octubre de 1792. La revisión de libros, según esta disposición, quedaba a cargo, conjuntamente, de un funcionario real y una persona comisionada por el Santo Oficio, quienes debían retener las obras expresamente prohibidas por edictos inquisitoriales y las que trataran de la revolución de Francia. El procedimiento seguido en las aduanas lo expone con notable claridad Ranz Romanillos, revisor real en la aduana de Zaragoza, al enviar al ministro Urquijo la lista de los libros examinados en 1798:

(7) A.H.N., Inquisición, leg. 4469, núm. 31. 
«algunos se entregaron al Comisario del Santo Oficio de esta Ciudad, por ser de los expresamente comprehendidos en sus Indices $\mathrm{y}$ edictos, $\mathrm{y}$ otros por tratar ex profeso de la Revolución de la República francesa se detuvieron en la Real Aduana...., y los demás fueron, como correspondía, entregados a sus dueños, sin retención ni agravio» (8).

No obstante, las dificultades con que se hallaron los revisores fueron notables $\left({ }^{9}\right)$ y no pocas las contradicciones en que incurrieron. Así, la aduana de Zaragoza, donde actúa Ranz Romanillos, permitió que se entregaran a su destinatario, el ex-jesuita Gregorio Garcés, un envío de 160 títulos llegado de Italia entre los que se hallaba la Histoire du clergé pendant la révolution française (ed. en 2 volúmenes, Ferrara, 1794) de Barruel, considerándolo, como el resto de los libros, «notoriamente corriente». Sin embargo, este mismo libro, y en la misma edición, fue retenido en un envío del mismo año destinado igualmente a un ex-jesuita, Félix Araflot $\left({ }^{10}\right)$.

Por otra parte, no se practicó con rigor la detención de todos los títulos prohibidos y los que se referían ex profeso a la revolución de Francia, pues muchos personajes disponían de licencia para leerlos. La misma aduana de Zaragoza, en el expediente al que acabamos de referirnos, entrega al canónigo de la ciudad José Sobrebia un envío que le llega de Francia con libros de Bossuet y los tres siguientes: Eloge historique et funèbre de Louis XVI, du nom Roi de France et de Navarre (Neufchatel, 1796), Les crimes de Robespierre et de ses principaux complices (Paris, 1797) e Histoire de la Conjuration de Louis Philipe Josef d'Orléans (Paris, 1796). Los funcionarios acompañan la entrega de la nota siguiente:

«Los quales libros aunque todos son prohibidos a excepción de las Obras de Bossuet, se han entregado sin embargo en el mismo acto al Interesado por haber éste exhibido licencia de leer y retener tales libros, expedida a su favor por el Inquisidor General.... en 9 de junio de 1794».

Las personas de cierta relevancia por razón de su cargo o por su relación con los medios cortesanos no cabe duda gozaron de ciertos privilegios en este punto. Gómez Labrador, por ejemplo, siendo Oidor de la Audiencia de Sevilla, recibió en 1794 las obras completas de Mably y otras de Locke y Pope,

(8) A.H.N., Estado, leg. 3136.

(9) Vid. L. Domergue, Le livre en Espagne au temps de la Révolution Française, Lyon, PUL, 1984, pp. 67-69.

(10) A.H.N., Estado, leg. 3136. 


\section{Revista de História das Ideias}

y dos años más tarde se hace cargo de un nuevo envío de libros de Voltaire y Rousseau, sin que le fuera detenido en la aduana (11). Al margen de esto, es sabido que en Madrid y otros puntos de España circulan con cierta facilidad obras relativas a la revolución francesa que, incluso, se venden en librerías. En 1801, por citar un caso, el librero madrileño Elías Ranz reconoce a la Inquisición haber comprado a un indivíduo llegado de París varios libros, entre ellos 400 ejemplares de una Historia de la Revolución Francesa, que tenía a la venta en su establecimiento $\left({ }^{\mathbf{1 2}}\right)$.

Aunque es indudable que la actitud más generalizada, tanto de las autoridades civiles como de las inquisitoriales, fue dura al respecto, se produjeron numerosas excepciones. Unas veces burlando la vigilancia, como han documentado, entre otros, Defourneaux, Domergue, G. Anes...; otras recurriendo a permisos especiales o a favores e influencias, hubo personas que lograron la bibliografía relativa a los acontecimientos revolucionarios franceses. Desconocemos qué pudo acontecer en el caso de Lugo, aunque al menos consta un dato: dispuso del favor de la Corte, pues en febrero de 1793, esto es, tan sólo tres meses después de tener lugar el examen de los libros que le envía Saubaigne desde Bayona, es nombrado Director de los Reales Estudios de Madrid ( $\left.{ }^{13}\right)$. Tal vez esto explique que en 1817 tuviera en su casa algunos volúmenes con títulos coincidentes con los de 1792. Es evidente, en cualquier caso, que conoció esa bibliografía y no sería infundado suponer que sus amigos del círculo de la condesa de Montijo tuvieran acceso a esta información.

\section{Coincidencias en los planteamientos básicos}

Resulta innecesario hacer un recuento de las obras relativas a la Iglesia constitucional francesa introducidas en España para admitir que se obtuvo información directa y precisa. Las noticias, por lo demás, no llegaron únicamente por la vía de las publicaciones. Appolis ha constatado la existencia de contacto epistolar de ilustrados españoles con Grégoire. Aunque parece que estas cartas no se han conservado, el testimonio del propio Grégoire y otros indicios confirman la importancia de tal vía informativa. El obispo de Barbastro, Agustín Abad

(11) Ibidem, idem.

(12) A.H.N., Inquisición, leg. 4474, núm. 5.

(13i) G. Demerson, "Un canarien....», p. 316. 
y Lasierra, la condesa de Montijo y la que Grégoire calificaba «la portion plus saine du clergé espagnol» recibieron noticias de primera mano a través del obispo de Blois y se manifestaron en clara consonancia con el proyecto de los constitucionalistas. En algunos casos se llegó, incluso, a una colaboración personal estrecha, como sucede con José Yeregui, quien proporciona información importante a Grégoire sobre el funcionamiento de la Inquisición española ( $\left.{ }^{14}\right)$.

Para los ilustrados españoles del grupo jansenista resultó de gran ayuda, además, el apoyo prestado a la Constitución Civil del Clero por el obispo Scipione Ricci. El Sínodo de Pistoia gozaba en los medios españoles de gran consideración y por eso habría que conceder un rango especial a las opiniones de Ricci difundidas en 1792 por España en un manuscrito titulado Memoria del Ilmo. Sr. Scipion de Ricci en respuesta a los Quaesitos que se le han hecha relativos a las presentes diferencias de la Iglesia de Francia. Ricci defiende claramente la obra de la Asamblea Constituyente, la obligatoriedad del juramento y la legitimidad del nuevo clero constitucional. El obispo italiano utilizó, además, un argumento que debió resultar determinante para muchos españoles, en especial porque el regalismo estaba muy acentuado entre ellos: el poder temporal está capacitado para introducir reformas en la disciplina exterior eclesiástica y mientras la Iglesia universal no las condene, no cabe objeción alguna. En cuanto al Papa, tampoco ha condenado formalmente nada, por lo cual no existe duda en cuanto a la iglesia francesa. Según Ricci, la condena hecha por Pio VI en los breves de 1791 y en concreto el del 13 de abril, Charitas...., no era determinante:

\footnotetext{
«es sabido - dice el obispo - que hasta ahora (el Papa) ha restringido sus quejas al solo Códice de las Decretales y a las reglas de la Cancelaría. Convendrá esperar a que hable como cabeça de la Iglesia según sus santas reglas. El Santo Padre cuando sostiene la posesión de los derechos temporales de su silla, no es creible que quiera interesar la religión. Aun auando esto fuese sería necesario agardar el consentimiento de la Iglesia universal. El papa condenó la elección de Melecio, y con todo no dejó de ser obispo y santo" (15).
}

(14) E. Appolis, ob cit., pp. 120-121 y 126-127. Actitud parecida adontó monseñor Tavira, persona de gran influio en los medios ilustrados y muy amigo de Jovellanos: vid. J. Saugnieux, Un nrélat éclairé: Don Antonio Tavira y Almazán (1737-1807), Toulouse, 1970, pp. 184-187 v 211-212.

(15) A.H.N., Inquisición. leg. 4430, núm. 21. En los años noventa la confusión respecto a la actitud del Papa ante la iglesia constitucional 
A pesar de todas las precauciones a tomar en España cuando se expresaban opiniones novedosas y del general ambiente hostil a los sucesos revolucionarios franceses, fueron frecuentes las exposiciones benevolentes hacia la iglesia constitucional. Una de ellas se debe a Félix Amat, prelado bien relacionado con el grupo de ilustrados al que venimos refiriéndonos y altamente considerado en la Corte. En 1803, en los días en que fue nombrado abad de San Indefonso, terminaba de escribir una monumental obra, Tratado de la Iglesia de Jesucristo o Historia Eclesiástica, sin duda la más importante del género aparecida en España entonces. En ella trata con notable objetividad de la Constitución Civil del Clero, señalando con precisión los argumentos de sus detractores y sus defensores. El único juicio personal de Amat es el siguiente:

"Luego que se publicó la Constitución Civil del Clero se declararon a su favor varios eclesiásticos, cuyas obras y palabras los hacían muy sospechosos en la fe. Pero no puede negarse que también estaban por la constitución algunos de ejemplares costumbres $\mathrm{v}$ mucho zelo contra la incredulidad» (16).

La ponderación de Amat es elocuente. No existe en su obra la retahíla de los calificativos utilizados contra la iglesia constitucional por el clero regular y los calificadores inquisitoriales del momento, quienes invariablemente suelen referirse al asunto con términos tales como «cisma», «usurpadores», «herejes», etc.

Con todo, la aceptación de la obra religiosa de la Asamblea francesa no se realiza sin ciertas reticencias. Es lógico que los ilustrados españoles que como veremos no aceptan los principios revolucionarios políticos, rechacen muchos aspectos de la obra francesa. Como apunta P. de Demerson, tal vez la opinión más generalizada coincidió con la que expresaba Tamburini (teólogo muy admirado en España) en Nouvelles Ecclésiastiques (1797): los clérigos constitucionales se han visto obligados a ceder en muchos puntos de disciplina externa como única posibilidad para salvar la religión ${ }^{\left({ }^{17}\right)}$. En consecuencia, los ilustrados españoles muchas veces defendieron la iglesia constitucional como hecho consumado a partir del cual había que procurar salvar en lo posible la pureza de la religión.

francesa es notable en España. Circularon todo tipo de atribuciones, falsas epístolas, breves, etc. Vid.. por ejemplo, la calificación de dos impresos en este sentido en A.H.N.. Inquisición, leg. 4429, núm. 24.

(16) F. Amat. Tratado de la Iglesia de Jesucristo.... T. XII, Madrid, Imprenta de Benito García y Cía., 1807, 2:" ed., p. 172.

(17) P. De Demerson, ob. cit., p. 274. 
Ahora bien, al mismo tiempo coincidían en un aspecto básico con la forma de proceder de la Constituyente: su actuación de carácter regalista y galicano. Se podía discutir tal o cual medida pero se consideraba un acierto el procedimiento de reforma seguido. Esto se ve perfectamente en la actitud de Joaquín L. Villanueva en la réplica a la famosa carta de Grégoire al Inquisidor General Arce.

Villanueva escribió una refutación directísima de la pretensión de Grégoire de acabar con la Inquisición española y realizar una serie de reformas religiosas $\left({ }^{18}\right)$. Pero en sus Cartas mantenía el presbítero español expresamente la validez de la intervención del poder temporal en la reforma de la disciplina externa de la Iglesia, que, en realidad, era el punto esencial a considerar en la obra de la Asamblea Francesa. Es decir, Villanueva rechaza la intromisión de Grégoire en la iglesia española y también aspectos fundamentales de la iglesia constitucional, pero acepta plenamente el procedimiento seguido en Francia. De esta manera, un escrito como éste, que suele ser considerado refutación de Grégoire y de la iglesia constitucional es en el fondo un apoyo al procedimiento reformista francés. Así lo entendieron los clérigos franceses emigrados que de inmediato denunciaron las Cartas a la Inquisición y de la misma opinión participaron los religiosos que hicieron la primera censura de la obra $\left(^{19}\right)$. De hecho, afirman unos y otros, Villanueva defiende a la iglesia constitucional, pues contínuamente reconoce el carácter episcopal de Grégoire y coincide de pleno con los «cismáticos» franceses en lo relativo a la reforma de la disciplina eclesiástica. La obra, en consecuencia, es peligrosa y se recomienda su prohibición, a pesar de constituir un alegato en defensa del Santo Oficio.

El inquisidor José de Amarillas no se conformó con estos pareceres, por tratarse de «una obra que además de estar escrita por un autor piadoso y bien opinado, establece los dere-

(18) A la carta de Grégoire al Inquisidor General Ramón J. de Arce (Vid. E. Appolis, Ob. cit., pp. 130-132) replica Joaquín Lorenzo Villanueva, con el seudónimo de Lorenzo Astengo: Cartas de un presbítero español sobre la Carta del ciudadano Grégoire, obispo de Blois, al señor Arzobispo de Burgos, Inquisidor General de España, Madrid, Cano, 1798, 169 pp.

(19) A.H.N., Inquisición, leg. 4460, núm. 16. El escrito de Villanueva fue denunciado primeramente (19-2-1799) por los presbíteros franceses emigrados Jaime Taurines y Bernardo Dufrechou ante el Tribunal de Murcia. En 1803 el expediente pasa al Tribunal de la Corte y allí efectúan una primera censura Fr. Luis de Pedro Bernardo y Fr. Lucas de Valencia (5-8-1803). La censura que cerró el expediente la firman Antonio Oliveros y Antonio Posada Rubín de Celis (13-8-1803). 
chos del Santo Oficio» y la remitió a nueva calificación a los canónigos de S. Isidro Antonio Oliveros y Antonio Posada Rubín de Celis. Estos defienden claramente a Villanueva y deben realizar auténticos malabarismos para simular las coincidencias doctrinales de fondo con la iglesia constitucional. Si trata a Grégoire con respeto es para mejor refutarlo, dicen, y reconocer capacidad en el poder temporal para intervenir en la Iglesia es la mejor manera de defender al Santo Oficio: «el objeto de ellas (las Cartas) es probar que los Príncipes tienen facultades para imponer penas temporales a los Hereges». Lo cual, sin duda, valía en ese momento para considerar la obra de Villanueva una defensa de la Inquisición, pero constituía, también, un alegato en favor del intervencionismo del poder temporal en asuntos relacionados con la Iglesia.

Oliveros y Posada condenan la obra de Grégoire, pero no se hallan en su censura invectivas, acusaciones de cisma y cosa por el estilo. Más bien existe un tono benevolente hacia el obispo francés, del que los canónigos madrileños ofrecen la siguiente imagen: «Habían corrido sus escritos por España; en esta Carta (la que envía a Arce) y en otros papeles publica sus trabajos por la religión y sus esfuerzos por sostenerla en Francia. Los Monitores que han inundado nuestra España aseguraban haber este Obispo y miembro de la convención resistido a los que en medio de ella lo convidaban a apostatar y lo amenazaban con las prisiones si no lo hacía; que él fue el primero quien después de la muerte de Robespierre clamó en la convención por la tolerancia de los cultos desterrada de la Francia por aquel monstruo. Esto se había publicado prescindiendo de su verdad. Por otra parte no constaba, ni se habían publicado en España formalmente los Breves de la Santidad de Pío VI que hablan de la constitución religiosa de la Asamblea, ni se habían hecho manifiestas las heregías del clero constituyentes, ni el Sumo Pontífice ha hablado de ellas en los Breves de Pacificación». En otro lugar afirman los canónigos que nada se logra llamando a Grégoire «intruso, cismático, herege, ladrón....» pues esta forma de proceder sólo consigue «agriar más los espíritus, fomentar la división y dificultar más la unión de este clero con la Santa Sede». En ningún momento de la censura se pone en duda el carácter episcopal de Grégoire y lo único que se discute es su intromisión en los asuntos internos españoles.

El inquisidor Amarillas; quien por su parte acabamos de ver califica a Villanueva de "autor piadoso y bien opinado», aceptó la censura de Oliveros y Posada y en el auto definitivo declara «benemérita del Santo Oficio una producción que defiende $\mathrm{y}$ establece sus derechos con un nervio poco común, 
así como la religión católica y potestad de los Reyes». Como se puede comprobar, la opinión del propio inquisidor no deja de entrañar peligro: en otros asuntos que no sean la defensa directa del Santo Oficio cabe, asimismo, la intervención del poder temporal.

\section{Rechazo de los principios políticos revolucionarios}

Lo sucedido en torno a las Cartas de Villanueva atestigua cómo penetran incluso en el seno de la Inquisición ideas favorables a la iglesia francesa, si bien es evidente que la generalidad de los inquisidores y de los actos del Santo Oficio condenaron y rechazaron de plano el experimento francés. Con todo, el simple hecho de recurrir a jansenistas tan caracterizados y conocidos como Oliveros y Posada para la calificación de una obra es todo un símbolo de la existencia de ciertos cambios en el seno mismo de la Inquisición. En ésta se habían introducido personas de inequívoco talante reformista, sobre todo tras el fugaz paso como Inquisidor General de Manuel Abad y Lasierra, hermano del obispo de Barbastro $\left({ }^{20}\right)$.

Es una constante, sin embargo, que en España incluso los defensores de la Iglesia constitucional ataquen los principios políticos y la obra de la revolución francesa. Se produce así una separación tajante en sus consideraciones: se acepta la $\mathrm{r} \in$ forma religiosa y se rechazan las transformaciones políticas. El motivo parece bastante claro, a nuestro juicio: antes de la revolución francesa habían calado profundamente en España las tendencias reformistas de signo galicano y jansenizante, por lo que resultó lógico aceptar su aplicación; las nuevas ideas políticas, sin embargo, conllevaban planteamientos generales más profundos que repugnaban al talante y a la condición misma de los ilustrados. La época del terror y la muerte de Luis XVI acabaron por hacer imposible una aceptación de esta realidad, al tiempo que la guerra contra la Convención creaba en España un indudable ambiente de hostilidad hacia la Francia republicana.

(20) Uno de los casos más sorprendentes en este sentido lo constituye el nombramiento de José Yeregui como ministro honorario del Consejo de la Inquisición en 1793, después del proceso que se le formó y en el que se le acusó extensamente de jansenista. Vid. Historia de la causa seguida en el Santo Tribunal de la Ynquisición contra el Señor D. Josef Yeregui...., manuscrito del autor (1793). 


\section{Revista de História das Ideias}

Félix Amat, Oliveros, Posada... rechazan los principios de la soberanía nacional, libertad civi, etc. No son éstos casos aislados, sino la tónica dominante entre los ilustrados. Amat se mostró siempre muy respetuoso con la forma de gobierno de Francia y al igual que el clero constitucional manifestó en varias ocasiones el principio de que el cristianismo es la religión de todos los pueblos y todos los gobiernos. Así se lo expuso a un clérigo de Paris:

«En tiempo de revolución todo buen sacerdote, sin meterse a examinar el derecho, se somete a todo gobierno que existe de hecho, y mira como abuso sacrílego del influjo que da la religión el valerse de ella para destruir algún gobierno existente».

En cartas a un presbítero francés emigrado, José Garcías, insiste varias veces en la conveniencia de aceptar la situación política francesa, abandonando reclamaciones polémicas, como las relativas a la recuperación de los bienes eclesiásticos $\left(^{(21}\right)$. Incluso insta el obispo español al presbítero francés a que preste sin reservas juramento a la Constitución republicana, $€ n$ la que no ve objeción alguna que hacer, salvo lo relativo a los bienes eclesiásticos $\left(^{\mathbf{2 2}}\right)$. Y sin embargo, en el dictamen que en 1803, dos años después del epistolario anterior, emite sobre la obra de Hervás y Panduro Causas de la revolución francesa, Amat declara el típico temor ilustrado a la revolución:

"conviene mucho que cuando sea preciso hablar al pueblo de tan delicadas materias (se refiere a la doctrina de la soberanía nacional) se le hable según las fundadísimas opiniones contrarias a las de Spedalieri, según las cuales la soberanía viene de Dios, de modo que en ningún caso puedan quitarla los pueblos a su legítimo soberano" (23).

Oliveros y Posada son tajantes en este asunto. En la censura de las Cartas de Villanueva, también fechada en 1803, rechazan la idea de «libertad civil», por ser contraria al Evangelio y a la religión, "cuya doctrina inspiró siempre la subordinación a las Potestades» y defienden a la monarquía frente a las acusaciones de despotismo provenientes de los filósofos $\left({ }^{24}\right)$.

(21) F. Torres Amat, Vida del Ilmo. Sr. Don Félix Amat, Arzobispo de Palmyra...., Madrid, Imprenta que fue de Fuentenebro, T. I, 1835 , p. 76, y T. II, pp. 100-101, respectivamente.

(22) Ibidem, T. II, p. 109.

(23) Ibidem, T. II, p. 174.

(24) A.H.N., Inquisición, leg. 4460, núm. 16. 


\section{Ilustrados e Inquisición}

Aunque caben matizaciones de diverso tipo, en conjunto los ilustrados españoles favorables a la reforma de la iglesia no desean, al menos antes de 1808 , un cambio político y, menos aún, que el pueblo protagonice cualquier acción revolucionaria. Georges Demerson lo apuntó con claridad a propósito de $\mathrm{Me}-$ léndez Valdés y recientemente Nicole Rochaix lo ha subrayado refiriéndose a Fr. Miguel de Santander, otro de los hombres proclives a las ideas religiosas de la iglesia constitucional $\left({ }^{25}\right)$. Así pues, parece que el pensamiento político dominante entre los ilustrados «jansenistas» españoles se ajusta a lo que expuso Jovellanos en carta a Alexander Jardine en 1794:

«....jamás concurriré a sacrificar la generación presente por mejorar las futuras. Usted aprueba el espíritu de rebelión, yo no: lo desapruebo abiertamente.... Creo que una nación que se ilustra puede hacer grandes reformas sin sangre, $\mathrm{v}$ creo que para ilustrarse tampoco sea necesaria la rebeliónn.

La educación y la reforma gradual, nunca brusca, es el camino correcto para los ilustrados $\left({ }^{\mathbf{2 B}}\right)$.

En España existe un sector de ilustrados favorable a la adopción de una vía revolucionaria antes de $1808\left({ }^{27}\right)$. Creo que otro grupo importante, al que nos venimos refiriendo en este trabajo, cuyo rasgo común es la primacía en sus preocupaciones por la reforma de la Iglesia, es antirrevolucionario (pero no contrarrevolucionario). Una parte de los componentes de este segundo grupo se integrará entre los afrancesados en 1808 y otra pasará al bando patriota. Entre estos últimos (es el caso de Villanueva y Oliveros, por citar a dos de los que nos hemos ocupado ahora) las ideas revolucionarias van ganando terreno paulatinamente y al final del periodo de las Cortes de Cádiz podemos considerarlos claros partidarios de la revolución. Pero antes de los sucesos de 1808 y de la actuación desafortunada de los monarcas españoles desde el motín de Aranjuez a las renuncias de Bayona, confían en la monar-

(25) N. Rochaix, «L'Eglise d'Espagne et la France: le cas de Miquel de Santandern, en J. Saugnieux, Foi et lumiere dans l'Espagne du XVIIIe siècle, Lyon, PUL, 1985, pp. 41-42 especialmente. Vid., sin embargo, la opinión en parte diferente de A. Elorza, "Cristianismo ilustrado y reforma política en Fr. Miguel de Santander», Cuadernos Hispanoamericanos, núm. 214 (1967), pp. 90-92.

(26) Carta de Jovellanos a A. Jardine (21-5-1794), en Jnvellanos, Obras Completas. T. II. Correspondencia, Edición de J.M. Caso González, Oviedo. 1985, pp. 635-636.

(27) Vid. A. Elorza. La idenlogía liberal en la ilustración española, Madrid, Tecnos, 1970, pp. 235 ss. 
quía ilustrada y en las reformas desde arriba. El testimonio personal ofrecido por Villanueva tal vez explique la situación: a propósito de las cartas contra Grégoire dice que trató de mostrar «la sinrazón con que se pretendía ver convertidas todas las monarquías en repúblicas»; que varios amigos le desaconsejaron la publicación del escrito, pero desoyó sus razones.

"Acaso columbraban ellos - comenta Villanueva - lo que no sospeché yo nunca, esto es, que el poder real llegase a convertirse en arma para abatir y arruinar la nación, y que la hipocresía vistiese el disfraz de la religión para infamarla y perseguirla» (28).

Es decir, antes de 1808 Villanueva - y cabe pensar que el conjunto de sus contertulios en casa de la condesa de Montijo - tiene confianza en la monarquía absoluta; evidentemente, la perdió más tarde, pero mantuvo sus ideas en cuanto a la reforma de la Iglesia. En las Cortes de Cádiz se repitieron los argumentos esgrimidos en los años noventa y se acordaron reformas muy similares a las ensayadas por la iglesia constitucional francesa. En definitiva, se mantenían las ideas en este campo, pero se cambiaban los métodos políticos. Quienes optaron por el bando afrancesado (Estanislao de Lugo, Félix Amat, Miguel de Santander...) también mantuvieron las ideas, pero difirieron de los anteriores en el método político, y prácticamente sólo en eso ${ }^{(29)}$.

(28) J.L. Villanueva, Vida literaria, vol. I, Londres 1925, p. 40. Villanueva publica, asimismo, en 1793 una obra claramente contraria a las ideas políticas revolucionarias: Catecismo de Estado según los principios de la Religión, Madrid, Imprenta Real, 309 pp. Según confiesa en su Vida literaria escribió este libro para «preservar a España del contagio que había convertido aquel reyno (Francia) en un teatro de horrores» (p. 38).

(29) Vid. un planteamiento general de la política religiosa de afrancesados y liberales en E. La Parra, "La reforma del clero en España. 1808-1814», en G. Dufour et Al., El Clero Afrancesado, Aix-en-Provence, 1986 , pp. 15-54. 